\title{
SRD5A2 Gene Polymorphisms and the Risk of Benign Prostatic Hyperplasia but not Prostate Cancer
}

\author{
Vimal Kumar Choubey ${ }^{1}$, Satya Narayan Sankhwar ${ }^{1}$, S Justin Carlus ${ }^{2,3}$, Anand \\ Narayan Singh ${ }^{1}$, Divakar Dalela ${ }^{1}, K_{\text {Kumarasamy Thangaraj }}{ }^{2}$, Singh Rajender ${ }^{4 *}$
}

\begin{abstract}
Background: Testosterone, a primary androgen in males, is converted into its most active form, dihydrotestosterone (DHT), by 5 $\alpha$-reductase type 2 (encoded by the SRD5A2 gene) in the prostate. DHT is necessary for prostatic growth and has five times higher binding affinity than testosterone for androgen receptors. We hypothesized that polymorphic variations in the SRD5A2 gene may affect the risk of benign prostatic hyperplasia and prostate cancer. Materials and Methods: We analyzed SRD5A2 gene polymorphisms in 217 BPH patients, 192 PCa cases, and 171 controls. Genotyping was undertaken using direct DNA sequencing. Genotype data were compared between cases and controls using a Chi square statistical tool. Results: We found that the A49T locus was monomorphic with ' $\mathrm{AA}$ ' genotype in all subjects. At V89L locus, the presence of ' $\mathrm{VV}$ ' showed a marginally significant correlation with increased BPH risk $(\mathrm{p}=0.047)$. At the (TA) ${ }_{n}$ locus, longer TA repeats were found to be protective against $\mathrm{BPH}(\mathrm{p}=\mathbf{0 . 0 0 3})$. However, neither of these polymoprhisms correlated with the risk of PCa. Conclusions: We conclude that $\mathrm{A49T}$ is monomorphic in the study population, VV marginally correlates with $\mathrm{BPH}$ risk, and longer (TA) ${ }_{n}$ repeats are protective against BPH. None of these polymorphisms affect the risk of PCa.
\end{abstract}

Keywords: $5 \alpha$-reductase type 2 - benign prostatic hyperplasia - genetic polymorphism - prostate cancer - SRD5A2

Asian Pac J Cancer Prev, 16 (3), 1033-1036

\section{Introduction}

Benign prostatic hyperplasia (BPH), a common disease of men above 50 years of age (Boyle and Napalkov, 1996), is characterized histologically by hyperplasia and hypertrophy of the prostatic cells and clinically by prostatic enlargement and lower urinary tract symptoms (LUTS). The evidence of BPH is found in $50 \%$ of males by the age 50 and in $90 \%$ of males by the age of 80 . (Berry et al., 1984). This disorder has two phases, one that involves no clinical signs and the other that manifests as disorders of urination resulting from urinary tract obstruction by an enlarged prostate (Isaacs, 1994). The aetiology and pathogenesis of BPH is still not known. Many hypotheses have suggested that $\mathrm{BPH}$ is a multifactorial disease, but it still lacks an integrated model of pathogenesis and progression. The only definitive risk factors for $\mathrm{BPH}$ are increasing age and an intact androgen system. Another prostatic disease, prostate cancer $(\mathrm{PCa})$, is the most frequent killer of men worldwide and is the second leading cause of death in men (Jamal et al., 2008). The incidence of PCa increased in the American population in the late 1980s and the early 1990s. This trend has also been observed in low-risk countries like India (Srinivas et al., 1995). PCa risk is strongly affected by the family history such that the risk increases 2- to 4-folds among men reporting PCa in father or brother, after adjustment for age and dietary factors (Heinlein and Chang, 2004). BPH is not a major cause of death like PCa, but it adversely affects the quality of life of the patients.

Testosterone, a primary androgen in males, is converted into its most active form, dihydrotestosterone (DHT), by $5 \alpha$-reductase type 2 (encoded by the SRD5A2 gene) enzyme in the prostate (Wilson et al., 1993). DHT has five times higher binding affinity than testosterone for androgen receptor (Wilbert et al., 2008); the receptorligand complex thus formed translocates to the nucleus to transactivate the target genes (Feigelson et al., 1996; Stanford et al., 1997). DHT is necessary for prostatic growth and development of male external genitalia. Two isoforms of $5 \alpha$-reductase (Type I and II) have been reported. Type I is expressed in liver, skin, and scalp and is encoded by the SRD5A1 gene located on chromosome 5 (Suzuki et al., 2001) while the type II enzyme is encoded by the SRD5A2 gene, which is mainly expressed in the skin and the prostate (Andersson and Russell, 1990). The gene encoding the type II enzyme is located on chromosome 2 (Locus 2p23) and has five exons and four 
introns (Thigpen et al., 1992).

The mutations/deficiencies in the SRD5A2 gene are associated with male pseudohermaphroditism; adult males with this condition have a vestigial prostate and do not develop BPH (Thigpen et al., 1992; Wilson et al., 1993; Imperato-Mc et al., 1979). SRD5A2 activity (conversion of testosterone to DHT) varies in different ethnic populations, and polymorphisms in the SRD5A2 gene have been identified to affect enzyme activity (Ross et al., 1992; Reichardt et al., 1995; Makridakis, et al., 1997). It is reported that higher SRD5A2 activity is found in Blacks than Asians, which parallels observed ethnic differences in the PCa risk. A49T substitution (a missense substitution of threonine for alanine at codon 49 due to a $\mathrm{G}$ to $\mathrm{A}$ transversion, rs9282858) increases steroid $5 \alpha$-reductase activity 5 -folds in vitro compared to the wild type gene, (Makridakis et al., 1999) while V89L substitution (a missense substitution of leucine for valine at codon 89 due to a $\mathrm{G}$ to $\mathrm{C}$ transversion, rs523349) results in about $30 \%$ reduction in enzyme activity both in vitro and in vivo (Makridakis et al., 1997). Another polymorphism, a (TA) dinucleotide repeat, in the 3' UTR also affects SRD5A2 activity. Three alleles, (TA) $)_{0},(\mathrm{TA})_{9}$, and (TA) ${ }_{18}$, are most commonly seen with frequency variation with ethnic changes; however, exact effect of this repeat on SRD5A2 activity has not been worked out.

Genetic epidemiological studies have shown large variations in the frequency of A49T, V89L, and (TA) repeat polymorphisms and in their association with $\mathrm{BPH} /$ PCa risk (Mohammad et al., 2005; Jun et al., 2010; Izmirli et al., 2011; El Ezzi et al., 2014). We have undertaken the present study to; 1) analyse the frequency of the SRD5A2 polymorphisms in India, 2) find if these polymorphisms affect the $\mathrm{BPH} / \mathrm{PCa}$ risk.

\section{Materials and Methods}

\section{Subjects}

The study was approved by the Institutional Human Ethics Committee (IEC) of the King George's Medical University, Lucknow. We recruited 580 subjects, which included $217 \mathrm{BPH}$ patients (age range 45 to 80 years, mean 63 years), 192 prostate cancer patients (age range 50 to 96 years, mean 66 years), and 171 control subjects (age range 45 to 75 years, mean 61.88 years) from the Department of Urology of the King George's Medical University at Lucknow. Inclusion criteria of BPH were; age $>45$ years, presence of LUTS, prostate weight $>25 \mathrm{~g}$ on ultrasonography (USG), American Urological Association Symptom Score $>7$, prostate specific antigen (PSA) $<4.0$ $\mathrm{ng} / \mathrm{ml}$, and an enlarged smooth prostate on digital rectal examination (DRE). Those with PSA in the range 4.0-10 $\mathrm{ng} / \mathrm{ml}$ were included only if ten core trans-rectal ultra sound (TRUS) biopsies were negative. In the PCa group, all the patients were biopsy proven cancers. Controls were healthy volunteers (staff employees of the institute and attendants of other patients visiting the hospital for minor non-prostatic medical and surgical problems) aged $>45$ years with normal DRE, PSA <4 ng/ml, no LUTS, and a negative family history for PCa. The subjects were recruited after informed written consent in response to a fully written and verbal explanation of the nature of the study. This study has not used any sample from our previous study (Singh et al., 2009) in which we analyzed samples from a different population.

\section{Genetic analysis of the SRD5A2 gene}

Genomic DNA was isolated from the peripheral blood using standard chloroform-phenol procedure for DNA extraction. The primers used for polymerase chain reaction (PCR) amplification of the SRD5A2 gene, including intron/exon junctions, were designed using Ensemble software/Gene Tool software and synthesized commercially by Eurofins, India. Conditions for PCR amplification along with primer sequences for each exon are detailed in our previous study (Singh et al., 2009). Briefly, the PCR products were sequenced directly by the dideoxy cycle sequencing chain termination method (Big Dye V3.1, Applied Biosystems) on ABI 3730 DNA analyzer (Thangaraj et al., 2003). Sequence editing and multiple alignments were carried out using AutoAssembler software (Applied Biosystems). Distinction between $(\mathrm{TA})_{0} /(\mathrm{TA})_{0},(\mathrm{TA})_{0} /(\mathrm{TA})_{9}$, and $(\mathrm{TA})_{9} /(\mathrm{TA})_{9}$ ) genotypes was done on the basis of size after running PCR products on a long range $2 \%$ agarose gel. Representative samples were subjected to gene scan on ABI 3730 to confirm the results.

\section{Statistical analyses}

The genotype distribution at all loci was compared between cases and controls. The low activity genotypes at V89L (VL and LL) were added together and compared against high activity genotype (VV) between cases and controls. Similarly, the genotypes with longer repeats $\left[(\mathrm{TA})_{0} /(\mathrm{TA})_{9}\right.$ and $\left.(\mathrm{TA})_{9} /(\mathrm{TA})_{9}\right]$ were added and compared against genotypes with shorter repeats $\left[(\mathrm{TA})_{0} /(\mathrm{TA})_{0}\right]$. Chisquare values were calculated using the online Vassar Stats Calculator (http://vassarstats.net). Two-sided P values of less than 0.05 were taken to be significant.

\section{Results}

We didn't observe any polymorphism at the A49T site. Table 1. Genotypes Distribution at V89L Locus in Prostate Cancer, BPH, and Controls

\begin{tabular}{lcccc}
\hline Groups & VV & VL+LL & p-value & OR (95\% CI) \\
\hline Controls (N=154) & 104 & 50 & $\begin{array}{l}\text { Taken as } \\
\text { reference }\end{array}$ \\
BPH $(\mathrm{N}=188)$ & 145 & 43 & 0.047 & $1.62(1.00-2.61)$ \\
PCa $(\mathrm{N}=129)$ & 97 & 32 & 0.15 & $1.45(0.86-2.45)$ \\
\hline Table 2. Genotypes Distribution at (TA)n Repeat Locus \\
In Prostate Cancer, BPH, and Controls
\end{tabular}

\begin{tabular}{|c|c|c|c|c|}
\hline \multirow[b]{2}{*}{ Groups } & \multicolumn{4}{|c|}{$(\mathrm{TA})_{\mathrm{n}}$ Repeats } \\
\hline & $(\mathrm{TA})_{0} /(\mathrm{TA})_{0}$ & $\begin{array}{c}(\mathrm{TA})_{0} /(\mathrm{TA})_{9}+ \\
(\mathrm{TA})_{9} /(\mathrm{TA})_{9}\end{array}$ & p-value & OR $(95 \% \mathrm{CI})$ \\
\hline $\begin{array}{l}\text { Controls } \\
(\mathrm{N}=171)\end{array}$ & 149 & 22 & $\begin{array}{l}\text { Taken as } \\
\text { reference }\end{array}$ & \\
\hline $\begin{array}{l}\mathrm{BPH} \\
(\mathrm{N}=217)\end{array}$ & 210 & 07 & 0.0003 & $\begin{array}{c}4.42 \\
(1.84-10.63)\end{array}$ \\
\hline $\begin{array}{l}\mathrm{PCa} \\
(\mathrm{N}=192)\end{array}$ & 177 & 15 & 0.11 & $\begin{array}{c}1.74 \\
(0.87-3.47)\end{array}$ \\
\hline
\end{tabular}


Table 3. Combined Genotypes Distributions at V89L and (TA)n Repeat Polymorphisms Loci

\begin{tabular}{|c|c|c|c|c|c|}
\hline \multirow[t]{2}{*}{ TA genotype } & \multicolumn{4}{|c|}{$\begin{array}{l}\text { V89L genotype (\%) } \\
\text { Odds ratio }\end{array}$} & \multirow[t]{2}{*}{ Fisher's exact $p$ value } \\
\hline & $\mathrm{V} / \mathrm{V}$ & $\mathrm{V} / \mathrm{L}$ & $\mathrm{L} / \mathrm{L}$ & Total & \\
\hline & \multicolumn{5}{|c|}{ Cases } \\
\hline$(\mathrm{TA})_{0} /(\mathrm{TA})_{0}$ & $138(73.4)$ & $38(20.2)$ & $5(2.6)$ & 181 (96.3) & $\mathrm{p}=0.71$ \\
\hline$(\mathrm{TA})_{0} /(\mathrm{TA})_{9}$ & $7 \quad(3.7)$ & $0 \quad(0.0)$ & $0(0.0)$ & $7 \quad(3.7)$ & \\
\hline$(\mathrm{TA})_{9} /(\mathrm{TA})_{9}$ & $\begin{array}{ll}0 & (0.0)\end{array}$ & $0 \quad(0.0)$ & $0(0.0)$ & $\begin{array}{ll}0 & (0.0)\end{array}$ & \\
\hline Total & $145(77.1)$ & $38(20.2)$ & $5(2.7)$ & $188(100.0)$ & \\
\hline & \multicolumn{5}{|c|}{ Controls } \\
\hline$(\mathrm{TA})_{0} /(\mathrm{TA})_{0}$ & $88(57.1)$ & $45(29.2)$ & $0(0.0)$ & 133 (86.4) & $\mathrm{p}=0.93$ \\
\hline$(\mathrm{TA})_{0} /(\mathrm{TA})_{9}$ & $16(10.3)$ & $5 \quad(3.2)$ & $0(0.0)$ & 21 & \\
\hline$(\mathrm{TA})_{9} /(\mathrm{TA})_{9}$ & $\begin{array}{ll}0 & (0.0)\end{array}$ & $0 \quad(0.0)$ & $0(0.0)$ & $0(0.0)$ & \\
\hline Total & $104(67.5)$ & $50(32.5)$ & $0(0.0)$ & $154(100)$ & \\
\hline
\end{tabular}

$\mathrm{PCa}, \mathrm{BPH}$, and control samples displayed 'AA' at this site. Our results suggest a marginally significant difference in the distribution of V89L genotypes between $\mathrm{BPH}$ and control groups $(\mathrm{p}=0.047)$, but not between $\mathrm{PCa}$ and control samples $(\mathrm{p}=0.15)$ (Table 1). A higher frequency of VL/LL genotypes in the controls suggested marginally protective effect of the substitution. Comparison of the genotypes at (TA) locus found highly significant differences between $\mathrm{BPH}$ and control groups $(\mathrm{p}=0.003)$, but not between $\mathrm{PCa}$ and control groups $(\mathrm{p}=0.11)$ (Table 2$)$. Higher frequency of long repeats in the controls suggested significantly protective effect of the substitution. Similarly, the frequency of the longer repeats in the control group was higher in comparison to the PCa group, but the differences were not significant (Table 2).

\section{Disequilibrium between V89L and (TA) ${ }_{n}$ loci}

The genotypes at V89L and (TA) $)_{n}$ repeat loci were cross-classified to look at the disequilibrium between the two sites (Table 3). V/V genotype among cases was $76.24 \%(138 / 181)$ for the (TA) $)_{0 / 0}$ genotype, $100 \%$ (7/7) for the (TA) $)_{0 / 9}$ genotype, while among controls it was $66.16 \%(88 / 133)$ for (TA) $)_{0 / 0}$ genotype and $76.19 \%$ $(16 / 21)$ for $(\mathrm{TA})_{0 / 9}$ genotype. Fisher's exact test using $3 \times 3$ contingency table showed no significant association between the genotype distribution at the two sites among cases $(p=0.71)$ or controls $(p=0.93)$. Since there was no significant association between the distributions of the genotypes at the two sites, further association analysis using the genotype combinations was not undertaken.

\section{Discussion}

We found A49T locus to be monomorphic in our population. All BPH, PCa, and control samples exhibited 'AA' at this locus. 'TT' has been associated with higher enzyme activity (Makridakis et al., 1999; Makridakis et al., 2000). ' $\mathrm{T}$ ' variant is most prevalent in Caucasians (3.5\%), followed by African-Americans, Asians or Hispanics, and it increases PCa risk. It has been reported that A49T substitution plays a significant role in high incidence of prostate cancer in black and Hispanic males and it is over-represented in those with advanced tumor or poor prognosis (Makridakis et al., 1999). Not much data is available to evaluate its correlation with BPH. It is interesting to note that A49T locus is monomorphic in the north Indian populations. Our previous study on prostate cancer in a south Indian population also found no variation at this locus. Since this substitution increases SRD5A2 activity, the presence of 'AA' in Indian populations may keep them at a lower risk of prostate problems arising due to increased DHT levels. In fact, it appears that A49T locus may be monomorphic in most of the Indian populations that could provide an edge against androgen related disorders.

We found V89L site to be highly polymorphic in the study population, and a marginally protective effect of this substitution was seen (Table 2). This could be due to lower activity of the enzyme with ' $L$ ' variant (Allen et al., 2001). A cohort study has shown that the presence of 'LL' confers lowest $5 \alpha$-reductase activity in PCa patients in an Asian population (Makridakis et al., 1997). An in vivo study has shown that V89L substitution reduced SRD5A2 enzyme activity by $39 \%$ in Asians (Makridakis et al., 1997). and by $10 \%$ in Caucasians (Makridakis et al., 1997; Allen et al., 2001). This could explain reduced risk of BPH in 'LL' carriers. A previous meta-analysis on V89L data from thirty-one studies found no difference in genotype distribution between PCa cases and control samples (Li et al., 2011). Similarly, a review of twentyfour case-control studies showed no association of V89L polymorphism with PCa risk (Jun et al., 2010).

Longer (TA) repeats showed strong protective effect against BPH (Table 3). It has been observed that Caucasians have longer (TA) repeats, which is associated with decreased transcription of the $5 \alpha$ - reductase, resulting in decreased $5 \alpha$-reductase enzyme activity. Longer (TA) n repeats also decreased DHT level, decreasing PSA production in PCa (Reichardt et al., 1995). This may explain reduced $\mathrm{BPH}$ risk in cases with longer (TA) repeats. The variation in the length of (TA) ${ }_{n}$ dinucleotides may be associated with RNA instability, resulting in production of altered amount of enzyme. However, exact impact of the length of (TA) repeats on SRD5A2 function has not been established in vitro; therefore, it is difficult to draw conclusion on exact impact of the repeat length on $\mathrm{BPH}$ risk and its mechanism of action. At least ten alleles of (TA) repeats, $0,8,910,17,18,19,20,21$, and 22, have been reported till date, (Reichardt et al., 1995) but only three (TA), (TA)9, and (TA) ${ }_{18}$ of them are common; (TA) $)_{0}$ being the most common in most of the populations, while (TA) ${ }_{18}$ is rare. We found (TA) $)_{0}$ variant to be the most 
frequent (87\% in controls, $96 \%$ in $\mathrm{BPH}$ and $97 \%$ in $\mathrm{PCa}$ ) and (TA) ${ }_{18}$ to be completely absent in our population. We found no significant difference upon data comparison between $\mathrm{PCa}$ and control groups.

In conclusion, A49T locus is monomorphic in the study population. VV at V89L locus may correlate with a marginally increased risk of $\mathrm{BPH}$, and longer $(\mathrm{TA})_{\mathrm{n}}$ repeats are protective against $\mathrm{BPH}$. None of the above polymorphisms affect the risk of PCa. Studies on ethnically divergent populations are encouraged to unveil ethnic specific differences in the association of SRD5A2 polymorphisms with $\mathrm{PCa}$ and $\mathrm{PBH}$.

\section{Acknowledgements}

The authors would like to thank the Ministry of Health and Family Welfare (MOH \& FW), Govt. of India, for financial support. Mr. Choubey would like to thank the Indian Council of Medical Research (ICMR), Govt. of India, for graduate fellowship [3/1/2/(10)/URO/10/NCDII]. We are indebted to the patients and control subjects for their participation in the study.

\section{References}

Allen NE, Forrest MS, Key TJ (2001). The association between polymorphisms in the CYP17 and $5 \alpha$-reductase (SRD5A2) genes and serum androgen concentrations in men. Cancer Epidemiol Biomarkers Prev, 10, 185-9.

Andersson S, Russell DW (1990). Structural and biochemical properties of cloned and expressed human and rat steroid 5-alpha-reductases. Proc Natl Acad Sci USA, 87, 3640-4.

Berry SJ, Coffey DS, Walsh PC, Ewing LL (1984). The development of human benign prostatic hyperplasia with age. J Urol, 132, 474-9.

Boyle P, Napalkov P (1996). Epidemiology of benign prostatic hyperplasia: current perspectives. Urology, 2, 7-11.

Das K, Peh YC, Pei LL. et al (2008). Shorter CAG repeats in androgen receptor and non-GG genotypes in prostatespecific antigen loci are associated with decease risk of benign prostatic hyperplasia and prostate cancer. Cancer Letters, 268, 340-7.

El Ezzi AA, Zaidan WR, El-Saidi MA, et al (2014). Association of benign prostate hyperplasia with polymorphisms in VDR, CYP17, and SRD5A2 genes among Lebanese men. Asian Pac J Cancer Prev, 15, 1255-62.

Feigelson HS, Ross RK, Yu MC et al (1996). Genetic susceptibility to cancer from exogenous and endogenous exposures. J Cell Biochem, 25, 15-22.

Heinlein CA, Chang C (2004). Androgen receptor in prostate cancer. Endocr Rev, 25, 276-308.

Imperato-Mc G J, Peterson RE, Gautier T, Sturla E (1979). Androgens and the evolution of male-gender identity among male pseudohermaphrodites with 5-alpha-reductase deficiency. N Engl J Med, 300, 1233-7.

Isaacs JT (1994). Etiology of benign prostatic hyperplasia. Eur Urol, 25, 6-9.

Izmirli M, Arikan B, Bayazit Y, Alptekin D (2011). Associations of polymorphisms in HPC2/ELAC2 and SRD5A2 genes with benign prostate hyperplasia in Turkish men. Asian Pac J Cancer Prev, 12, 731-3.

Jamal K, Patel P, Sooriakumaran P (2008). Minimally invasive surgical modalities in the management of localized prostate cancer. Expert Rev Anticancer Ther, 8, 957-66.

Jun L, Ralph J, Coates MG (2010). Steroid $5 \alpha$-reductase type 2
(SRD5 2 2) gene polymorphisms and risk of prostate cancer: a huge review. Am J Epidemiology, 171, 1-13.

Li X, Huang Y, Fu X, et al (2011). Meta-analysis of three polymorphisms in the steroid-5-alpha-reductase, alpha polypeptide 2 gene (SRD5A2) and risk of prostate cancer. Mutagenesis, 26, 371-83.

Makridakis NM, Ross RK, Pike MC, et al (1999). Association of mis-sense substitution in SRD5A2 gene with prostate cancer in African-American and Hispanic men in Los Angeles, USA. Lancet, 354, 975-8.

Makridakis N, Ross RK, Pike MC, et al (1997). A prevalent missense substitution that modulates activity of prostatic steroid 5-alpha-reductase. Cancer Res, 57, 1020-22.

Makridakis NM, di Salle E, Reichardt JK (2000). Biochemical and pharmacogenetic dissection of human steroid 5 alphareductase type II. Pharmacogenetics, 10, 407-13.

Mohammad TS, Giske U, Eila CS, et al (2005). Association between polymorphisms in the steroid 5 - $\alpha$ reductase type II (SRD5A2) gene and benign prostatic hyperplasia and prostate cancer. Urologic Oncology, 23, 246-53.

Petitti DB (2001). Approaches to heterogeneity in meta-analysis. Stat Med, 20, 3625-33.

Reichardt JK, Makridakis N, Henderson Be, et al (1995). Genetic variability of the human SRD5A2 gene: implication for prostate cancer risk. Cancer Res, 55, 3973-75.

Ross RK, Bernstein L, Lobo RA, et al (1992). 5-alpha-reductase activity and risk of prostate cancer among Japanese and US white and black males. Lancet, 339, 887-9.

Salman MT, Ursin G, Skinner EC, Dessissa T, Reichardt JK (2005). Associations between polymorphisms in the steroid 5-alpha reductase type II (SRD5A2) gene and benign prostatic hyperplasia and prostate cancer. Urol Oncol, 23, 246-53.

Singh R, Krishnaswamy V, Singh P, et al (2009). Longer (TA) repeats but not A49T and V89L polymorphisms in SRD5A2 gene may confer prostate cancer risk in south Indian men. J Androl, 30, 703-10.

Sobti RC, Gupta L, Singh SK, et al (2008). Role of hormonal genes and risk of prostate cancer: gene-gene interactions in a North Indian population. Cancer Genetics Cytogenetics, 185, 78-85.

Srinivas V, Mehta H, Amin A, et al (1995). Carcinoma of the prostate-state at initial presentation. Int Urol Nephrol, 27, 419-22.

Stanford JL, Just JJ, Gibbs M, et al (1997). Polymorphic repeats in the androgen receptor gene: molecular markers of prostate cancer risk. Cancer Res, 57, 1194-98.

Suzuki T, Darnel AD, Akahira JI, et al (2001). 5-alfa-reductase in human breast carcinoma: possible modulator of in situ androgenic actions. J Clin Endocrinol Metab, 86, 250-57.

Thangaraj K, Singh L, Reddy AG, et al (2003). Genetic affinities of the Andaman Islanders, a vanishing human population. Curr Biol, 13, 86-93.

Thigpen AE, Davis DL, Milatovich A, et al (1992). Molecular genetics of steroid 5-alpha-reductase 2 eficiency. J Clin Invest, 90, 799-09.

Wilbert DM, Griffin JE, Wilson JD (2008). Characterization of the cytosol androgen receptor of the human prostate. J Clin Endocrinol Metab, 56, 113-20.

Wilson JD, Griffin JE, Russell DW (1993). Steroid 5-alphareductase 2 deficiency. Endocr Rev, 14, 577-93.

Xia L, Yan H, Xuping F et al (2011). Meta-analysis of three polymorphisms in the steroid-5-alfa-reductase, alfa polypeptide 2 gene (SRD5A2) and risk of prostate cancer. Mutagenesis, 3, 371-83.

Zhenhua LI, Tomonori H, Kenji M, et al (2003). Association of V89L SRD5A2 polymorphism with prostate cancer development in a Japanese population. J Urology, 169, 2378-81. 